\title{
Keeping the Peace: How Equity is Leveraged through Safe Schools Policy
}

\author{
Laurie Corrigan, Lorayne Robertson \\ University of Ontario Institute of Technology, Canada
}

\begin{abstract}
This paper describes research which examines the implementation at the school level of a safe schools policy which has elements of both anti-discrimination education and peacekeeping. In the process, both the formal text of this policy and its school-level implementation are considered. The authors present a brief history of safe school policies in Ontario, Canada, juxtaposing this with the concurrent development of equity and anti-discrimination policies in the same jurisdiction. The study's research questions ask how school administrators are responding to safe schools policies which are intended to build more inclusive schools. The participants are secondary school vice principals in several district school boards. The findings indicate that school leaders enact safe schools policies with intentions of fairness without necessarily referencing recent or longstanding policies for either safe schools or equity. The study also finds some evidence of educating students informally toward more respectful, anti-discriminatory practices. The researchers conclude that in spite of new policy which includes more progressive and restorative approaches to safe schools, policy enactment in some Ontario schools may still be more reflective of a process of keeping the peace rather than teaching anti-discrimination. The authors speculate that the provincial safe schools policy could be used as one tool to leverage equity initiatives.
\end{abstract}

\section{Introduction}

Policy analysis allows a deeper consideration of policy texts by considering their contexts and by attempting to identify the values underlying or within a policy. In this paper, the authors apply a policy analysis lens to reflect on the findings of a research study which took place in Ontario, Canada. This is in keeping with Ozga's contention almost a quarter of a century ago to "bring together structural, macro-level analysis of education systems and education policies, and micro level investigation, especially that which takes account of people's perception and experiences" [1] p. 359. The present study examines school leaders' (micro level) responses to cyber events which impact their students, and their reflections in practice about the provincial safe schools' policy (macro level). In the analysis of this research, the authors find that school leaders' policy compliance is reflective of their sense of doing what is right by their students and their communities, rather than focusing strictly on complying with provincial (or macro) policy directives.

Additionally, the authors report on how the lack of familiarity with recent and historic safe school policy and legislation does not prevent school leaders from taking action that is both progressive and punitive in order to respond to instances of bullying, cyberbullying, and online aggression. A third key finding of this study is that, even with the advent of more progressive and restorative approaches to school safety, the focus of anti-discrimination education appears to be relying on the policy lever [2] (Steer et al.) of a responsive, event-driven form of safe school policy - keeping the peace, although there are other elements to the policy which focus on restorative practices and anti-discrimination education.

\section{Context}

\subsection{Education policy development in Canada}

The historical development of policy in this section examines two types of policies developed for schools in the province of Ontario: safe schools policy and anti-discrimination or equity policies. The responsibility for elementary, secondary and postsecondary education in Canada was assigned to the 10 provinces and 3 territories by the Constitution Act of 1867 [3], so safe school policies fall within the purview of individual jurisdictions (provinces and territories). The province of Ontario has the largest population of any Canadian educational jurisdiction. Canada currently has no national education policies related to bullying in schools or online bullying such as, for example, the Australian National Safe Schools Framework [4]. Some federal policies, however, such as the Canadian Charter of Rights and Freedoms 
[5] are reflected in policies created at the provincial level.

\subsection{Keeping, making, or building peace}

Bickmore [6] makes distinctions between school district education policies which are primarily designed for keeping the peace, making peace, and building peace. She argues that aspects of all three approaches should be embedded in a framework that explicitly and implicitly teaches equity and tolerance.

She describes peacekeeping as the process by which control and exclusion are exercised. This approach is reflected in policies which include terms such as violence prevention and zero tolerance and can include "mandated codes of conduct" [6] (p. 78). She notes that these types of peacekeeping measures carry a risk of being applied disproportionately to some segments of the school population.

Bickmore sees that peacemaking provides more opportunities to manage conflict and provide students with social skills within and in addition to the curriculum. While some of these activities promote mediation skills among peers, other activities which attend to critical issues or power and voice can open spaces for the exercise of democratic citizenship, such as class meetings.

Peacebuilding policies recognize that inequities exist in society and in schools, and comprehensive programming is needed to address them. According to Bickmore [6], peacebuilding goes beyond simply resolving the dispute and focuses instead on restoration, which is the repair of the relationship. Teaching about equity and anti-discrimination is a part of peacebuilding because power is an underlying current in bullying, teasing and harassment in schools [6].

\subsection{Safe schools and anti-discrimination}

The development of safe schools policy (peacekeeping) in Ontario appears to be in alignment with its anti-discrimination education approaches (peacebuilding) but it has also come into direct conflict with them. For example, the Ontario Human Rights Commission in 2003 reported concerns that the Ontario Safe Schools Act, 2000 was discriminatory [7]. Prompted by reports of this collision, the authors analyzed the development of safe school policies in Ontario against the backdrop of the development of anti-discrimination approaches in Ontario and employed the perspective of Bickmore's policy analysis framework: peacekeeping, peacemaking and peacebuilding [6].

Early anti-discrimination efforts in Ontario policies began with the official recognition that there should not be bias in curriculum materials. Canada is characterized by diversity - a recent census reveals that Canadians have more than 200 diverse ethnic origins and Ontario is its most populous and diverse province [8].

In 1968, a Royal Commission review of elementary education in Ontario reported that Ontario schools were a mosaic of students from 160 countries who spoke 81 languages. The report cautioned that educators should no longer assume that children came from a middle class Anglo-Saxon background [9] (p. 39). The official call to revise the curriculum to accommodate other races, religions and cultures in school materials did not come until twelve years later, however, in the form of a document entitled, Race, Religion and Culture in Ontario School Materials (nd) [10]. This document defined bias, prejudice, discrimination and stereotypes for textbook publishers and schools.

In 1989, Ontario introduced policy for secondary schools to have codes of conduct [11]. In 1993, guidelines for policy development: Antiracism and Ethnocultural Equity in School Boards was published by the new government, the New Democratic Party (NDP) (who held the leadership in the provincial legislature from 1990 - 1995). These guidelines required schools to develop policies to "equip students with the knowledge, skills, attitudes and behaviours needed to live and work effectively in an increasingly diverse world, and encourage them to appreciate diversity and reject discriminatory attitudes and behaviour" [12] (p. 5). In response, some local educational jurisdictions developed equity-focused curriculum initiatives [13] but little is known about the broader, provincial impact of these developments.

In 1994, in response to perceived concerns of growing violence in schools, the same NDP government enacted the Violence-Free Schools Policy, 1994 [14] which required district school boards to respond to violent incidents in their schools. This policy could be described as mostly peacekeeping, but it also had elements of peacebuilding reflective of a social-democratic party orientation. The Violence-Free Schools Policy mandated violence prevention in the curriculum and identified areas of discrimination (such as race, gender, sexual orientation, disability, income and appearance). This policy also required schools (not only secondary schools) to have codes of behaviour which identified that abuse, bullying or discrimination "on the basis of race, culture, religion, gender, language, disability, sexual orientation or any other attribute is unacceptable" [14] (p.19). According to the policy, parents, students, and 
communities would review the codes of conduct for their local schools.

In the neighbouring United States, a similar approach was advocated for school discipline, including the introduction of violence prevention and conflict resolution programs [15].

The presence of these equity initiatives in the safe schools and curriculum policies in Ontario was, however, short-lived. In 1995, with the election of a Conservative government in Ontario, the social programs and policies for equity and affirmative action were severely cut back or eliminated [16] [17]) in what has been termed, "an all-out assault on antiracist education and inclusive practice" [16] (p. 112). When the Conservative government came to power, its key focus was on making schools more accountable and more profitable and providing information to parents. When they introduced new curriculum initiatives which focused on meeting expectations and accountability for schools, Ontario parents received the new curriculum online at the same time as the schools, a process which has not changed significantly since then.

Included in the new Conservative government's platform were policies which advocated a zero tolerance approach to school discipline. The codes of behaviour for schools were standardized by a code of behaviour for all schools in the province, the Code of Conduct for Ontario Schools, 2000. This code was later included in the Safe Schools Act, 2000 (Bill 81).

The Safe Schools Act, 2000 gave teachers the right to suspend students and principals the power to expel students for up to a year [18]. At the same time, this act took away discretionary powers from the schools. This act required schools to suspend students for a growing list of offenses such as swearing at a teacher or committing acts of vandalism. The policy also included mandatory requirements to expel students for certain offenses [18]. This act did not include initiatives for equity and anti-discrimination.

This zero tolerance approach was also a hallmark of school discipline initiatives in the United States during the 1990's although in the American scenario, there were also gun control considerations [15]. Zero tolerance as it was advocated in American jurisdictions was intended to have clear consequences for serious offences as well as programs for expelled students, violence prevention and conflict resolutions programs [19].

The Ontario Safe Schools Act, 2000 has been described as having a zero tolerance approach although the term itself is not found in the policy or in American school policies [19]. This approach was challenged, however because, while it appeared on the surface to provide a more consistent approach to bullying in schools, it was found to be unfair [6].
According to Daniel and Bondy, the unfairness was caused by its blanket approach to problems without considering the circumstances and needs of individual students. The Safe Schools Act (2000) did not alter the previous language from the Education Act that included the consideration of mitigating circumstances to be considered and applied to individual students but in spite of this, high needs students and racialized students were overly disadvantaged by the policy and were overrepresented in the statistics for suspensions and expulsions. The Ontario Human Rights Commission made a subsequent settlement with the Ontario Ministry of Education which resulted in a shift in Ministry policy away from zero-tolerance policies [6]. In 2005 another new government, led by the Liberal party, convened a Hate Crimes Community Working Group and subsequently revised the Code of Conduct to address hate propaganda.

In 2006, the Ministry of Education established a Safe Schools Action Team (an advisory committee of the Minister of Education) which examined longstanding issues of poverty and marginalization of certain student groups and proposed an agenda for a safe schools policy [20]. Among their recommendations was the requirement that schools revisit the importance of a school climate which was free from bias and discrimination, that emphasized violence prevention, and that made recommendations for progressive discipline policies. These recommendations reflect the anti-discrimination (or peacebuilding) elements of the earlier Violence-Free Schools policy (1994). In addition, one of the recommendations required that school boards offer empowerment programs such as conflict resolution and restorative practices, which align with Bickmore's schema of peacemaking. All three elements of keeping the peace, restorative practices and equity-promoting school climates were reflected the next policy, in the Accepting Schools Act, 2012 or Bill 13 [21].

\subsection{Safe schools in the digital era}

The Accepting Schools Act, 2012, both responded to earlier concerns with the overly-strict zero tolerance policies but also introduced some key elements which are reflective of a new era of digital communication. This policy expands the definition of bullying to address cyber-bullying. In keeping with an earlier focus on equity which was introduced in the 1993 and 1994 policies of the NDP government, the 2012 policy requires district schools boards to have equity and inclusive education policies in place. Schools are required to repond to all incidents of discrimination (including harassment and bullying) 
which come to the attention of the school. Another key change is that electronic means of bullying (cyber-bullying) is now included in the definition of bullying. The legislation also includes consequences for other harmful cyber offenses such as assuming another person's identity or communicating personal material online that can be accessed by other persons.

Another significant change with the new Accepting Schools Act is that schools are clearly established as the nexus for the reporting of harmful cyber events. Schools are also required to provide prevention programs, intervention programs, and progressive discipline for violations of the Provincial Code of Conduct. These changes have their origins in policies circa 1993/1994 but also include more recent shifts in policy from the Safe Schools Action Team [20] to include non-punitive interventions which increase individual responsibility (such as facing those they have wronged) and decrease exclusion (specifically suspension from school). These nonpunitive interventions are operationalized through the use of restorative practices.

\section{Theoretical Considerations}

\subsection{Policy development at the macro and micro levels}

In the research described here, the provincial policies represent the macro level of policy development. McLaughlin reminds us that, as a policy is put into practice at the local level, there are important local variations in how the policy is enacted because policies are enacted by people based on their local contexts. These local interpretations of policy can be reflective of the constituent base at the micro site, or they may indicate levels of resistance [22].

Multiple, intersecting factors affect the implementation of social policies in particular which tend to be messy and contextualized in their implementation. McLaughlin states that, "policymakers can't mandate what matters" [22] (p. 172) and the people involved at the micro level will make choices about how to implement in the local context. Even if the policy is clear at the macro level, there may still be implementation variations at the micro, or local level. Those persons implementing a policy need to have the capacity to address the key priorities of the policy. As such, training is a key factor in implementation. Local training can heighten engagement toward the policy. McLaughlin also posits that a certain degree of "muddling through" at the initiation of a policy at the micro level might be considered a positive sign of implementation, or an adaptive response [22].

\subsection{The research study}

The research study reported here sought to explore how school administrators were responding to the new safe school policy imperatives which included peacekeeping measures but also to more restorative approaches within a continuum of responses to cyber events and cyber misbehaviour.

The context of this policy implementation considers the history of safe school policies in Ontario relative to the building of equity and inclusive education policies, and the underlying philosophical stances which are evident in both of these policy discourses. It is important to consider the historical context, because policies respond to contextual factors such as changes in government, and new policies often build on previous policies, so they carry elements of earlier policies forward. Ontario has had a range of safe school policies and the pendulum of school discipline has swung from policies which approached both safe schools and equity considerations in the early 1990's to zero tolerance approaches without equity elements, and then back to safe school approaches which include conflict resolution, restorative practices, antidiscrimination, and equity-building approaches in the present era.

One of the research questions guiding this study was, "How do secondary school administrators employ or filter policy directives when responding to student incidents of online aggression and cyberbullying?" In order to respond to this question, the first step was a review of safe schools policy in Ontario. Next, the views of school administrators in several Ontario school districts were sought.

\section{Methodology}

Qualitative data methods were selected to investigate how the Accepting Schools Act, 2012 was being implemented at the local secondary school level. Because vice principals in Ontario secondary schools are the leaders charged with school discipline, the participants selected were nine vice principals from three school districts. There were some challenges with finding district school boards who would consent to the research, citing concerns regarding student privacy. That being said, every effort was made in the study to protect student, school and district confidentiality, including masking the gender of respondents and limiting the reporting of incidents where details might identify the region or the respondent. 
The vice principals were invited to participate on a NING, a private social media platform. Each week during the six weeks of the study, the vice principals were prompted to respond to questions about student cyber misbehaviour and provincial safe school policies. The moderator of the Ning asked the vice principals how they were responding to cyber incidents and their awareness of the policies.

Mixed data methodologies were used to gather data from the vice principals. The moderator of the NING posted questions each week for the participants, and encouraged them to elaborate on their views regarding the safe school policies, the cyber events taking place in their schools, their responses to these events, and their explanations of why they responded in certain ways to cyber events. The NING captured the vice principals' responses anonymously, and each participant could view other participants' responses which were masked for gender and school board through the use of avatars.

The qualitative questions were open-ended in order to provide more of a window on the nuanced considerations of the school leaders and illustrate their foundational beliefs and motivations in policy implementation. This kind of data collection and analysis allowed for an understanding of school leaders' key priorities during implementation of the new Accepting Schools policy.

\subsection{Data analysis}

The first step undertaken in the data analysis was to gather all of the vice principals' comments from the NING and read them through for a general sense of the data. This was done even though one researcher had been present for the duration of the NING as the moderator posing the questions to the participants and asking for clarifications. All of the vice principals' comments were collated to gather a sense of their individual and collective positions. General response themes began to emerge.

Next, the data were coded in two ways. First the data were organized week-by-week in response to the reflective prompts. Following that, the data were organized differently by looking across all of the responses from each respondent for all six weeks. This allowed the data to be examined more carefully from the perspective of each respondent's key points and meanings.

The key themes which emerged were identified because they were recurring, because they seemed important to the participants, or because the participants were introducing new ideas (unexpected themes). These key themes or categories are reported next in the findings section.

\section{Findings}

When school leaders were asked to indicate their degree of knowledge of the recently legislated Bill 13 (or the Accepting Schools Act), their survey responses revealed that knowledge about the actual legislation was diverse. Five respondents reported that they had limited knowledge, two respondents had some knowledge, and three respondents reported that they had considerable knowledge of the legislation. As a result, the link to the e-legislation was provided in the NING along with the prompts related to it so that school leaders could refer to the actual policies during their online discussions.

The quantitative survey indicated that two thirds of the respondents were female. Most of the vice principals were between the ages of 35 and 45 , and one third were between the ages of 45 and 60 . Most were new to their role - two thirds had between zero and three years in their role and 1/3 had between 4 and 6 years. Most of the school leaders in this study were new to administration.

This quantitative data belied the qualitative data that followed. While most of the school leaders indicated that they did not have considerable or even a small degree of knowledge of Bill 13, they were nevertheless taking decisive action when cyberbullying and online aggression took place, and they indicated that they were aware of the "obligation" they had to keep schools safe. After familiarizing themselves with the legislation, the vice principals in the study next responded to a series of prompts through the NING.

One prompt asked

"How has Bill 13 affected the work you do in schools? What other policy or legislation has affected your work? In what ways? What policies or rules do you think about when you are resolving safe school issues?"

The vice principals did see the value of the legislation in connection with the work they do and they viewed it positively in two ways. First, it provided direction and information. For some school leaders, the legislation provided helpful and explicit information that could be shared with students. These administrators used terms such as: direction, clear, streamlines, guidelines, guidance, defines and compels. One vice principal said that "Bill 13 has given school administrators clearer direction and guidance when dealing with students." Another vice principal said Bill 13 "defines bullying explicitly, and it is helpful to have a detailed definition to which I can refer." This school leader continued to explain that "[T]his legislation compels the administration to 
notify both the parents of the student harmed as well as the student who has harmed someone ...something that is ingrained in our practice."

Secondly, school leaders reported that the legislation gave support to practices that were in place in response to cyberbullying and online aggression prior to the new policy's existence. These respondents used the terms solidifies, supports, and give credence to their practices as administrators. One respondent stated that, "Effective school communities and administrators were already addressing these issues prior to the implementation of Bill 13." The vice principal further explained that "For obvious reasons, it is really important that this is included as students spend more and more time with these technologies."

One element of the Accepting Schools Act is the introduction of restorative practices. The findings in this study would appear to support the enactment of recent shifts in policy that are intended to include non-punitive interventions that increase individual responsibility and decrease exclusion. Based on this small study, this shift is taking place in schools. This shift includes suggestions from the Safe Schools Action Team [20] of the Ontario Ministry of Education that include the use of restorative practices. According to the findings of this study, these new measures could include parent contact, restorative practices, and progressive disciplinary measures. Findings also indicate that most of these school leaders had some degree of training in restorative practices but not extensive training.

Only one other policy was referred to in this study and that was one respondent's reference to an individual district school board's code of conduct. Notably, this respondent also felt that redemption and reintegration were as important as the consequences that were to be considered under Bill 13 when it came to cyberbullying and online harassment.

The vice principals were also asked

"What in your view is cyberbullying?

What does this term mean to you in relation to your experience as a VP?

How is it distinguished from other negative online communication?"

In spite of what first appeared to be a cursory understanding of Bill 13, school leaders understood and could articulate what cyberbullying meant to them in their roles. "Negativity and bullying has [sic] gone on since Socrates taught, but cyberbullying adds a new dimension to the role of the vp" said one respondent. Throughout their postings, the vice principals made distinctions between cyberbullying and online conflict, citing repetition of events, power imbalances, and harassment as characteristics of the former. Cyberbullying, one respondent contended, "uses online means and applications to harass another person. This can be in the form of direct communication with the victim (emails, chats, posts on their apps) or online communication online [sic] about that person." Another respondent indicated that "Cyberbullying is the use of technology to repeatedly intimidate and harass someone."

Vice principals felt that cyberbullying included direct and indirect references to another student whether that student was named or unnamed. While intent was identified as an aspect of cyberbullying, it was also mentioned that a lack of intent did not preclude it.

The vice principals distinguished online conflict from cyberbullying, indicating that "the victim sometimes is being more hurtful than the person they are upset with." Another vice principal indicated that the "vast majority of online disputes are not cyberbullying" but are indicative of relational conflict.

Vice principals indicated that there were both positive and negative aspects to social media and its use by students with complex implications for their role as administrators. They said that they spent "an inordinate amount of time 'sorting and sifting' information on social media." The potential for public shaming was cited as a great concern as "young people are given so much power in social media to broadcast their unkind thoughts that might have been either whispered or scribbled on a passed note in the past". However, the school leaders said that while there were negative aspects to online communication, it nevertheless leaves "hard evidence" or a "digital footprint" that they could use in their investigations.

For the most part, other policies such as equity and inclusive education policies were not considered in the context of negative online behaviour and cyberbullying, perhaps because most of the administrators had between 0 and 3 years of experience in the role. In addition, Bill 13, the Accepting Schools Act was widely perceived to be a helpful policy both for the reinforcement of previous practices already in place as well as for future action necessary in what one correspondent described as, "creating a safe school environment and responding to the activities of students despite location and time of day."

School leaders were also asked to reflect upon their role in the context of school policy. They were asked

"How do you perceive your role as an administrator in the context of legislation like Bill 13? In the context of media (including the Internet and newspapers)?" 
When they reflected on their roles as administrators in the context of the legislation, vice principals repeatedly reported feeling a sense of "obligation." These school leaders spoke of the serious obigations they felt they had in the context of the legislation as well as the expectations of parents. The vice principals also spoke of their responsibility to create a welcoming climate in their schools and to keep students safe.

As indicated earlier, vice principals saw the negative and positive aspects of social media. One school participant spoke of the potential of social media and other technologies to educate. This vice principal also conceded that while there were negative behaviours connected with social media, there were, however, other students who used social media responsibly.

The vice-principals seemed to be very aware of the potential lack of confidentiality associated with online postings, and were careful in their responses. While the participating vice principals used the NING to record their responses to the research questions, there was compliance but only limited interactivity within this private social network. Responses to questions typically were not met with additional commentary or questions from other participants which was an unexpected outcome of this study.

In summary then, the findings indicate that schools are undergoing changes in the types of situations that needed to be addressed, due to student participation in digital contexts, both during and outside of school time. The policies which have been provided to guide school responses to student conduct have a history of placing emphasis in different areas, which is reflected in the findings of this study.

\section{Conclusion}

This study focuses on how policy is enacted in the local arena, and it indicates that the vice-principals in the study are relying on their understandings of safe schools' policy, restorative practices, and equitable practices in order to serve the needs of students and parents, and also the public good.

It is helpful in policy research to review the historical events and understand the contexts and influences within which legislation has been developed over time. The analysis in this research indicates that education policies reflect both the politics of the times and the changing circumstances.

Because of the changing circumstances of a ubiquitous social media presence, it is now incumbent on Ontario schools to investigate and address the impact of cyberbullying and cyber misconduct on students and their families, even though the cyber incidents may be occurring outside of school time and off school property. This research reflects that the school administrators in Ontario who responded to this study are taking this level of new responsibility in stride and are finding ways to investigate cyber misconduct and restore security and dignity to the victims. In the process, the vice principals in the study also indicate that they also use these same circumstances to educate students.

It is important to consider how students may be advantaged or disadvantaged by policies and to investigate the literature and evidence in that regard. Our analysis of the history of safe schools policies in Ontario, although brief, points to the need for change to ensure that students' voices are heard equitably and their rights to schooling without harassment are respected in the process of building safe schools. In this perspective, this study finds that elements of antidiscrimination legislation which were evident in earlier curriculum guides (such as [12]) are now beginning to re-emerge in official Ontario policy although there is no evidence in the present study that these elements are receiving concerted attention. In this sense, we agree with Kazepides that policies without clearly-stated values can appear to be chameleonic as they respond to different political interests [24].

One of the exciting findings in this research is that, even without a great deal of detailed knowledge about Bill 13, secondary school vice principals are responding to the issues that online aggression brings to their schools such as cyberbullying and harassment and attempting to redress the wrongs and stay in closer touch with parents throughout this process.

Their actions, alongside a series of policy shifts and progressions over the last 15 years in the province of Ontario, reveal how school leaders both interpret and are guided by safe schools policies in a concerted effort that responds to the times and their particular circumstances. We hope that the findings of this study will encourage other researchers to investigate how policy and practice are being enacted to make schools safer, but also to consider how schools are becoming more equitable and inclusive for students in their jurisdictions.

\section{References}

[1] Ozga, J. (1990). Policy Research and Policy Theory: a comment on Fitz and Halpin 1. Journal of Education Policy, 5(4), 359-362.

[2] Steer, R., Spours, K., Hodgson, A., Finlay, I., Coffield, F., Edward, S., \& Gregson, M., (2007). 'Modernisation' and the role of policy levers in the learning and skills sector. 
Journal of Vocational Education and Training, 59(2), 175192.

[3] Constitution Act Canada (1867).

[4] Cross, D., Epstein, M., Hearn, L., Slee, P., Shaw, T., \& Monks, H., (2011). National safe schools framework: Policy and practice to reduce bullying in Australian schools. International Journal of Behavioral Development, 0165025411407456.

[5] Canadian Charter of Rights and Freedoms, s 2, Part I of the Constitution Act, 1982, being Schedule B to the Canada Act 1982 (UK), 1982, c 11.

[6] Bickmore, K., (2004). Discipline for democracy? School districts' management of conflict and social exclusion. Theory \& Research in Social Education, 32(1), 75-97.

[7] Daniel, Y., \& Bondy, K., (2008). Safe Schools and Zero Tolerance: Policy, Program and Practice in Ontario. Canadian Journal of Educational Administration and Policy, 70, 1-20.

[8] Statistics Canada, (2013). Immigration and Ethnocultural Diversity in Canada.

[9] Hall, E. M., \& Dennis, L. A., (1968). Living and learning. The Report of the Provincial Committee on Aims and Objectives of Education in the Schools of Ontario.

[10] Race, Religion, and Culture in Ontario School Materials: Suggestions for Authors and Publishers. (nd). Ontario: Ministry of Education.

[11] Ministry of Education. (1989). Ontario schools: Intermediate and senior divisions (Grades 7-12/OACs) program and diploma requirements. Revised edition. Queen's Printer for Ontario.

[12] Ontario Ministry of Education and Training. (1993). Antiracism and ethnocultural equity in school boards: Guidelines for policy development and implementation. Toronto.

[13] Robertson, L., (1998). Educators' responses to equity in-service. (Doctoral dissertation). University of Toronto.

[14] [Ministry of Education and Training (1994). The violence-free schools policy: Ministry of Education for Ontario: Queen's Printer for Ontario.

[15] Casella, R., (2003). Zero tolerance policy in schools: Rationale, consequences, and alternatives. The Teachers College Record, 105(5), 872-892.

[16] Dei, G. J., \& Karumanchery, L. L., (1999). School reforms in Ontario: The marketization of education and the resulting silence on equity. Alberta Journal of Educational Research, 45(2), 111.
[17] Delhi, K., (1996) "Between 'market' and 'state?' Engendering education change in the 1990s," Discourse studies in the cultural politics of education, 17 (3) 363-76.

[18] Legislative Assembly of Ontario (2000, June). Bill 81, Safe Schools Act.

[19] Winton, Sue., (2011). "Managing conduct: a comparative policy analysis of safe schools policies in Toronto, Canada and Buffalo, USA." Comparative Education 47.2: 247-263.

[20] Ontario Ministry of Education (2006). Safe schools policy and practice: An agenda for action from the Safe Schools Action Team. Toronto: Ontario Ministry of Education. Access date 15 October, 2015.

[21] Legislative Assembly of Ontario. (2012, June). Bill 13, Accepting schools Act, 2012.

[22] McLaughlin, M. W., (1987). Learning from experience: Lessons from policy implementation. Educational evaluation and policy analysis, 9(2), 171-178.

[23] Kazepides, T., (1995). The logic of educational policy. Canadian Journal of Education/Revue canadienne de l'education, 272-283. 